\title{
Role of advertising agencies in behavior change communication
}

Population Council

Follow this and additional works at: https://knowledgecommons.popcouncil.org/departments_sbsr-rh

Part of the Demography, Population, and Ecology Commons, Family, Life Course, and Society Commons, International Public Health Commons, and the Public Health Education and Promotion Commons How does access to this work benefit you? Let us know!

\section{Recommended Citation}

Population Council. 2010. "Role of advertising agencies in behavior change communication," Shaping Demand and Practices to Improve Family Health Outcomes in Northern India Policy Brief no. 13. New Delhi: Population Council. 


\section{Role of advertising agencies in behavior change communication}

\section{Background}

The role of advertising agencies (AAs) in social communication for development in India has evolved over the years. While earlier their role was limited to preparing mass media materials, AAs are now adopting a wide range of approaches including infotainment, advocacy, social mobilization and interpersonal communication (IPC) to promote targeted behavior change. Indeed, AAs now have specialized units dedicated to social communication that are involved in research, analysis, planning, strategizing and implementing communication programs.

Given their extensive experience in reaching rural populations using integrated multimedia approaches, AAs can provide valuable insights on the critical issues to be considered when planning an innovative behavior change communication (BCC) strategy to promote positive family health outcomes such as institutional delivery, postpartum care, early and exclusive breastfeeding, timely and appropriate initiation of complementary feeding, immunization and postpartum contraception for birth spacing in rural settings.

In 2009, R K Swamy BBDO, a premier AA in India, and a partner in the Population Council-led Consortium, conducted a qualitative study of AAs to: document their experiences with regard to planning and implementing BCC campaigns on social and health issues for rural populations; explore media planners' perspectives regarding the challenges faced in implementing these campaigns and possible strategies to make them more effective; and understand the role of the Directorate of Advertising and Visual Publicity (DAVP), the nodal multi-media unit of the Ministry of Information and Broadcasting, Government of India in reaching rural populations with information on government policies and programs. The findings of this study will help in planning appropriate BCC strategies and identifying potential partnerships with leading AAs to implement these strategies in the most effective manner. The study was funded by the Population Council as a subcontract, from an award granted by the Bill and Melinda Gates Foundation.

\section{Methodology}

A representative sample of AAs was selected based on three criteria: (a) annual turnover of at least INR 3 billion; (b) prior experience in developing and implementing BCC campaigns in the social and health sector; and (c) experience in the innovative use of media channels to reach below the line groups. Based on these criteria, apex AAs were identified, and 15 organizations were selected for the study in consultation with the Population Council.

A detailed guideline was prepared for the indepth interviews. Senior program mangers in the selected AAs were interviewed in detail by an experienced professional from RK Swamy BBDO. An expert in qualitative research from the Population Council also participated in the interviews. Transcripts of the interviews were prepared and analyzed.

Although 15 AAs were selected, only 9 interviews could be conducted. The key reason was that, given the extremely competitive nature of the advertising world, several agencies were reluctant to share

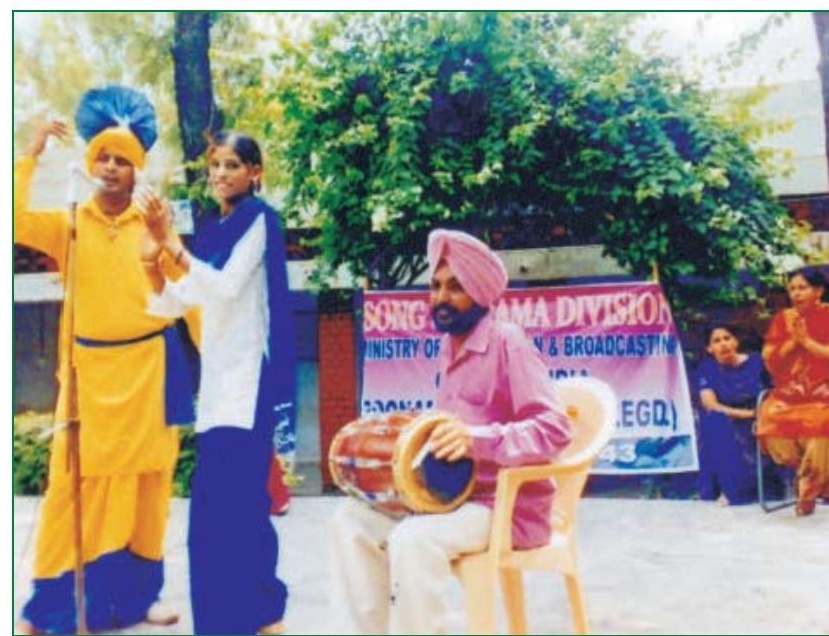




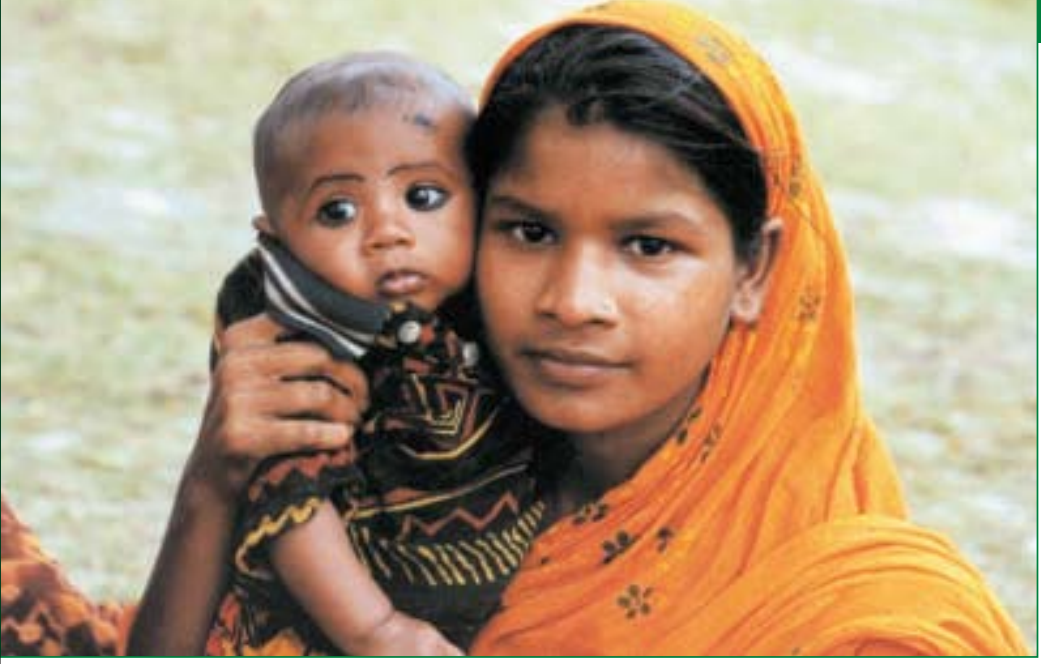

information on clients and best practices with "a rival advertising organization".

\section{Key findings}

Experiences in the social/rural sector: While sharing their experiences on social communication, strategic planners were of the view that communication strategies can be effective only if key inputs such as advocacy, social mobilization and mass media tools complement each other and the campaign aims to achieve clearly defined goals ${ }^{1}$.

Managers felt that due to the complexity of the issues and the limited reach of the mass media in rural settings, it is critically important to engage at the individual and community level for an effective BCC campaign. While the mass media creates awareness, it cannot address all the information needs of different target groups; IPC can, however, provide detailed information that allows people to make informed decisions.

Communication for behavior change involving rural and marginalized populations requires information to be provided in a language that is familiar, culturally acceptable and disseminated in locally appropriate settings.

Communication initiatives based on sound research, with audience-specific messages using multiple channels are effective in influencing behavior change. It was repeatedly noted that different communication media do not compete with each other for resources.

Effective BCC campaigns should be based on sound evidence-based research and built on theories of behavior change. Findings from formative studies should be used for planning BCC campaigns and determining the resources to be allocated to each media channel so as to optimize investment and maximize reach.

It was also noted that communication strategies must be holistic, moving beyond individuals to include other key stakeholders such as community members, service

${ }^{1}$ S. Prasad and M. Singh. 2010. "Role of advertising agencies in behavior change communication," in M.E. Khan, Gary Darmstadt, T. Usha Kiran and D. Ganju, eds. Shaping Demand and Practices to Improve Family Health Outcomes in Northern India: Exploring Partnerships. New Delhi: Population Council.

providers and decision-makers at different levels. In addition, strategies need to be based on comprehensive formative studies and promote messages that are aligned and reinforced by different media and channels. Some media experts argued that for sustained behavior change, community norms as well as the policy environment must be taken into account, making advocacy necessary at both the community and policy making levels. Accordingly, AAs strongly emphasized the need to develop an advocacy plan as part of an overall communication strategy, as reflected in the following quotes:

"As in many developmental projects, advocacy plays a critical role in improving family health outcomes. Advocacy takes place at different levels. At the level of the government or bureaucracy, program ownership is critical. For this, involving the government machinery at the state, district, block and down to the Panchayat level is even more critical."

\section{"What happens often is that we implement our communication strategy but we forget to plan and implement an advocacy strategy."}

Media planners were of the view that AAs need to be involved in the $\mathrm{BCC}$ campaign from the planning to the implementation stage to ensure message consistency and effective program implementation.

Managers identified Goli ke Hamjoli, the World Health Organization's ORS campaign, Jasoos Vijay, Bula Di, Vimla Rani and Balbir Pasha as examples of successful BCC campaigns in the social sector.

Challenges: Media planners felt that while several social communication initiatives in the rural sector have succeeded in creating awareness, they have had limited success in changing the prevailing mindset and initiating sustained behavior change. During discussions, several constraints in achieving the desired impact were identified, including the limited role of AAs in the planning process, their lack of involvement in determining the resources for media mix, and unrealistic timeframes for designing and implementing BCC campaigns. Managers noted that AAs often play only an ad hoc role in BCC campaigns: "We are associated with a campaign for message design but are neither involved in strategy development nor in disseminating our creative ideas. Often guidelines for message development are provided by the funding agency, leaving little room for innovation."

Managers were of the view that coordinating with government ministries and departments is an extremely challenging task. For example, bureaucratic processes, lack of transparency in sharing ideas with AAs and resistance to innovation impede the timely progress and implementation of BCC campaigns. Further, multiple stakeholders and differing perspectives within a ministry lead to lack of clarity regarding campaign objectives and strategies. However, it was felt that partnering with the government is critical for scaling up any social sector program as the 
government has access to vast resources, which can ensure the wide reach and sustainability of the program.

Often, due to the short duration of BCC campaigns, program review, feedback and modification are limited. Further, AAs are not involved in the monitoring and evaluation process and results are not shared with them; as a result, AAs cannot take the learning to the next project.

\section{Directorate of Advertising and Visual Publicity (DAVP):} DAVP can play a key role in implementing BCC campaigns to improve family health outcomes. DAVP provides singlewindow services to 96 client ministries (1,111 departments). It is also mandated to assist ministries in developing communication strategies.

DAVP disseminates information on government policies and programs using a media mix including the print media advertisements, printed materials, outdoor publicity (hoardings, billboards and banners), exhibitions and audiovideo spots. DAVP's publicity campaigns are cost effective as its rates are lower than commercial rates.

It has a large audience reach, covering population groups living in remote areas of the country as well. Approximately 5,000 newspapers are empanelled with DAVP, of which some 200 are large newspapers, and while the rest are medium or small newspapers with effective reach at the regional level. Over 100 radio channels and 169 TV channels carry DAVP's media spots. Approximately 90 agencies are associated with DAVP to create content and disseminate information.

DAVP has network of 32 field exhibitions units spread across the country that disseminate information on social and development issues through multi-media exhibitions. These units function as a vital communication link between the government and the people.

Challenges: While DAVP could be an effective partner in implementing a BCC strategy nation-wide, it faces several challenges in its functioning. For example, DAVP has to meet the needs of different client ministries and is required to handle a large volume of work on a day-to-day basis; however, its human resources are limited and lack the required skills. As a result, it is a challenge for DAVP to fulfill its mandate of social communication.

As DAVP's media planning is based on the principle of social equity, the organization does not use the "most effective media at an appropriate cost;" rather, it seeks to include a certain proportion of smaller/less effective media--both print and electronic media--in its campaigns. Consequently, the impact of the campaign is diluted.

As client ministries are responsible for message content and design, DAVP's role is often limited to disseminating the information given by the client. Moreover, as media selection depends to a large extent on the available budget rather than its effectiveness in reaching the target audience, appropriate media channels are not used.
Future roadmap for DAVP: DAVP's mandate should be reviewed in the context of the growing role of the media in promoting social issues, equity-based social change and human rights, and wherever feasible, new emerging technologies could be used to achieve these objectives. There is an immediate need to build the capacity of its staff at both the organization and field level. DAVP's financial management system would need to shift from a model based on social justice, fixed rates and a government salary structure to a business model, with competitive rates and salary packages so as to attract the best skilled professionals to work in a competing market environment.

As the nodal agency for positioning multi-media initiatives within the government, DAVP should be allowed greater flexibility and space in selecting outreach communication tools, identifying target audiences and themes for intervention and determining the media planning process thereafter.

In order to reduce DAVP's workload and improve efficiency and transparency, the possibility of outsourcing certain "non-core" activities could be considered. Increasing the use of information and communication technology (ICT) within the organization would also improve its efficiency.

\section{Implications for the BCC strategy}

Selection of an appropriate media mix: Currently, BCC campaigns are not evidence-based or built on information provided by the funding agency. Communication strategies for effective behavior change need to be informed by a situation analysis that identifies key audience segments; levels of media exposure and media habits of the audience; and the barriers and facilitating factors at the individual, community and system level with regard to the desired behavior.

AAs and researchers need to work together to gain a clear understanding of the local context and prevailing community norms. Based on these inputs, a combination of mass media and IPC communication tools should be adopted. Mass media and IPC can play a complementary role, reinforcing each other based on audience needs. It is suggested that for rural audiences (of whom the majority

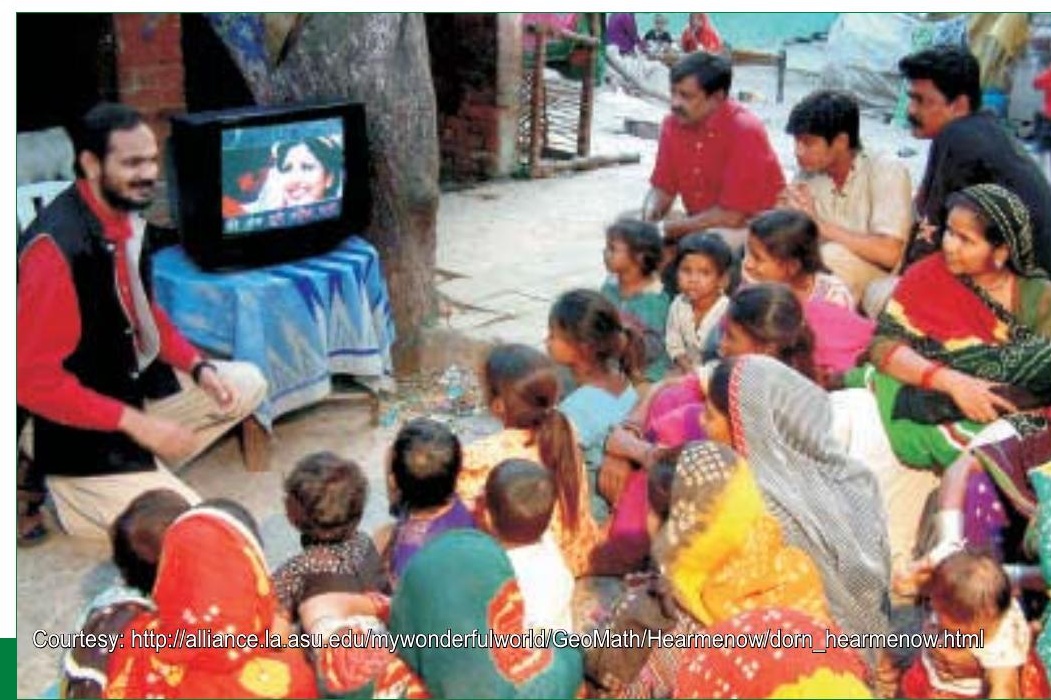


are women and non-literate populations), an integrated approach with IPC taking the lead complemented by the mass media would be effective.

Collaboration with the government ensures wider coverage and sustainability: As discussed earlier, though working with the government is a challenge, it is the most feasible strategy to access government resources and scale up BCC interventions in the social sector. AAs and government ministries and departments should collaborate to design and implement BCC campaigns if sustained behavior change is to be achieved on a wide scale.

\section{Advocacy should constitute part BCC} strategy: Advocacy at all levels- -with the central and state government, partner organizations and community/ key stakeholders--is vital and should be an integral part of BCC strategies in the social sector. As a senior manager noted: " $A$ campaign is orphaned if not designed under the umbrella of advocacy communication."

New and mid-media can play an important role: Technological innovations can play a definitive role in communicating with rural audiences. However, new media and ICTs should be used with caution in rural settings, keeping in mind issues of accessibility and infrastructure support, and their effectiveness in meeting the objectives of the BCC strategy. Mid-media, for example, community radio, could be an effective tool to promote behavior change. AAs could be asked to provide technical assistance to selected NGOs in community radio programming to reach the unreached and difficult-to-reach population groups.
Need for a single window creative agency: Bringing on board a single AA from the time of planning to the final stage of dissemination ensures effective program implementation, consistency of messages and synchronized use of different media. As a manager said: "It is important to have the message consistent across all platforms and therefore you need one central agency that will be in charge from the beginning, making sure all the different levels of communication are functioning at the same time and are consistent. This is a massive logistical exercise."

Monitoring and evaluation to be built into the BCC strategy: A major lacunae identified by most AAs was the lack of monitoring and evaluation systems in BCC campaigns. In general, AAs are involved in $\mathrm{BCC}$ campaigns on an ad-hoc basis, and lack of information on the progress of the campaign prevents them from evaluating its effectiveness. It was suggested that AAs should also be involved in the monitoring and evaluation of campaigns.

Most BCC are of short duration and increase in knowledge is considered to be an indicator of success. AAs should be accountable for assessing the impact of BCC campaigns, measured primarily in terms of sustained behavior change rather than increase in knowledge.

Reviews of successful campaigns in India indicate that evidence-based long-term campaigns (spanning 4-5 years), an integrated multi-media approach, on-going monitoring and program modifications, if necessary, are critical for ensuring sustained behavior change.

Suggested citation: Population Council. 2010. Role of advertising agencies in behavior change communication, Policy Brief No. 13. New Delhi: Population Council.

For additional information, contact: Population Council, Zone 5A, India Habitat Centre, Lodi Road, New Delhi 110003, or email info-india@popcouncil.org, or contact R K SWAMY BBDO Private Limited, 1-E/1, Jhandewalan Extension, New Delhi 110055.

\section{(2) Population Council}

Research that makes a difference

\section{Abt}

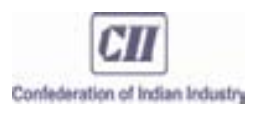

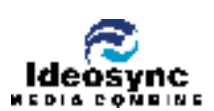


The opinions expressed in this publication do not necessarily reflect the views of the funding agencies.

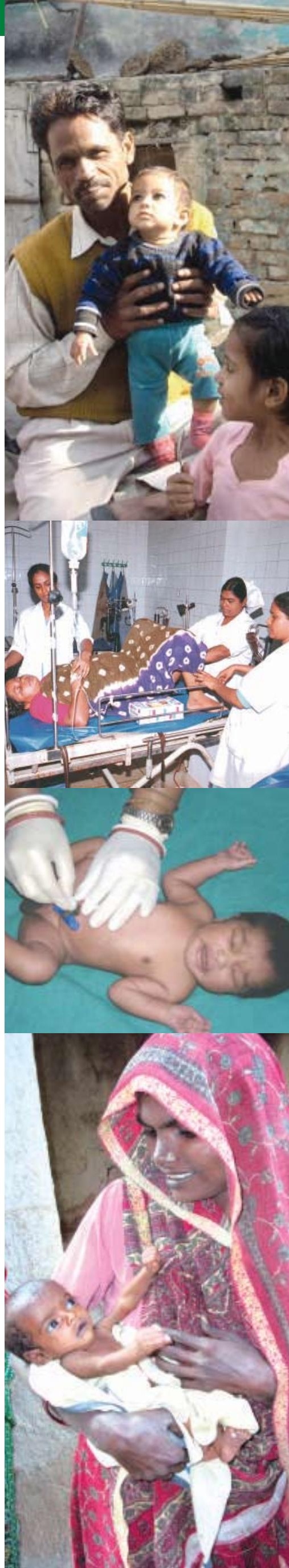

